\title{
ANGIOARCHITECTURE AND CLINICAL PRESENTATION OF BRAIN ARTERIOVENOUS MALFORMATIONS
}

\author{
Marcio Luiz Tostes dos Santos', Zeferino Demartini Júnior², \\ Luiz Afonso Dias Matos ${ }^{3}$, Antonio Ronaldo Spotti ${ }^{4}$, Waldir Antônio Tognola ${ }^{5}$, \\ Atos Alves de Sousa ${ }^{6}$, Rosangela Minto Tostes dos Santos ${ }^{7}$
}

\begin{abstract}
The purpose of this study was to correlate the angioarchitecture of brain arteriovenous malformations (AVM) with their clinical presentation. A total of 170 patients with AVM 78 males and 92 females, were studied. Univariate and multivariate analyses were conducted in order to test the associations between morphological features and clinical presentation. The most frequent clinical presentations at diagnosis were hemorrhage in 89 (52\%) patients, headache in 79 (46\%), focal neurological deficit in 54 (32\%), and seizure in 52 (31\%). According to the Spetzler-Martin classification, grade I was found in 15 patients, II in 49, III in 55, IV in 41, and grade V in 10 patients. AVM with small nidus size, single feeding artery and single draining vein were associated with hemorrhage. Hemorrhage was positively associated with Spetzler-Martin grade I and negatively with grade V. The association between seizure and large nidus size was positive, however negative with small nidus size.
\end{abstract}

KEY WORDS: brain arteriovenous malformations, angioarchitectural features, clinical presentation.

\section{Angioarquitetura e apresentação clínica de malformações arteriovenosas encefálicas}

Resumo - O objetivo deste estudo foi correlacionar a angioarquitetura de malformações arteriovenosas encefálicas (MAV) com sua apresentação clínica. Foram estudados 170 pacientes portadores de MAV, sendo 78 do sexo feminino e 92 do masculino. Análises univariada e multivariada foram efetuadas para testar associações entre características morfológicas e quadro clínico. As principais formas de apresentação clínica no momento do diagnóstico incluíram hemorragia em 89 (52\%) pacientes, cefaléia em 79 (46\%), déficit focal em 54 (32\%) e convulsão em 52 (31\%). De acordo com a classificação de Spetzler e Martin, 15 pacientes tinham MAV grau I, 49 grau II, 55 grau III, 41 grau IV, e 10 grau V. MAV com nidus de tamanho pequeno, aferência e eferência únicas foram associados à hemorragia. Hemorragia foi positivamente associada com grau I e negativamente com grau V. A associação entre convulsão e nidus de tamanho grande foi positiva, porém negativa com nidus de tamanho pequeno.

PALAVRAS-CHAVE: malformações arteriovenosas encefálicas, angioarquitetura, apresentação clínica.

Brain arteriovenous malformations are morphological abnormalities characterized by direct communication between arteries and veins, without interposition of capillary bed therefore without resistance to blood flow? AVMs have three distinct components: feeding artery, nidus, and draining vein. Clinical manifestations are related with type, site and size of malformation. Hemorrhage is the main cause of mortality and persistent morbidity in patients with AVM, ranging from $30 \%$ to $86 \%$ of cases $^{2}$. Other clinical manifestations include seizure in $27 \%$ of the patients, headache in $25 \%$ and focal neurological deficit in $8 \%{ }^{3-6}$.

Besides technological development in the last decades, the physiopathology as well as the natural history

\footnotetext{
Unidade de Neurocirurgia Endovascular do Serviço de Neurocirurgia do Hospital de Base de São José do Rio Preto, São José do Rio Preto, SP, Brasil: ${ }^{1} \mathrm{MD}, \mathrm{MS}$, Head of the Unit of Endovascular Neurosurgery at Hospital de Base de São José do Rio Preto, SP, Brazil; ${ }^{2} \mathrm{MD}$, Neurosurgeon, fellow of Unit of Endovascular Neurosurgery at Hospital de Base de São José do Rio Preto, SP, Brazil; ${ }^{3}$ MD, Neurosurgeon of Unit of Endovascular Neurosurgery at Hospital de Base de São José do Rio Preto, SP, Brazil; ${ }^{4} \mathrm{MD}$, PhD, Professor of the Department of Neurological Sciences at Faculdade de Medicina de São José do Rio Preto, SP, Brazil; ${ }^{5} \mathrm{MD}$, PhD, Head of the Department of Neurological Sciences at Faculdade de Medicina de São José do Rio Preto, SP, Brazil; ${ }^{6} \mathrm{MD}$, PhD, Professor of the Department of Neurosurgery at Faculdade de Ciências Médicas de Minas Gerais and Santa Casa de Belo Horizonte, MG, Brazil; ${ }^{7}$ Psicóloga do Centro de Diagnóstico e Tratamento Neuropsicológico, São José do Rio Preto, SP, Brazil.
}

Received 17 September 2008, received in final form 19 December 2008. Accepted 12 March 2009.

Dr. Marcio Luiz Tostes dos Santos - Hospital de Base / Unidade de Neurocirurgia Endovascular - Avenida Brigadeiro Faria Lima 5544 - $15090-000$ São José do Rio Preto SP - Brasil. E-mail: neurocirurgiaendovascular@yahoo.com.br 
of AVMs remains incompletely elucidated and its treatment is still a challenge to neurosurgeons.

The purpose of this study was to morphologically characterize a series of brain arteriovenous malformations, trying to establish a correlation with their clinical presentation.

\section{METHOD}

One hundred and seventy patients with brain AVMs, admitted at the Vascular and Endovascular Neurosurgery Unit of Hospital de Base at São José do Rio Preto, São Paulo, Brazil, were studied between January, 2001, and January, 2007. Seventy-eight (46\%) were male and 92 (54\%) female, and age ranged from 1 to 77 years (34.1 $1 \pm 15$ years) at presentation.

This study was approved by the Research Ethics Committee of the São José do Rio Preto Medical School (FAMERP).

Other types of vascular malformations such as dural fistula, carotid-cavernous fistula, vein of Galen malformations, angiomas, and telangectasias were excluded from this study ${ }^{7}$.

Hemorrhagic presentation was always confirmed by $\mathrm{CT}$ and/ or MR brain imaging ${ }^{8}$. The other clinical presentations were stratified into seizure, focal neurological deficit, headache, or other/non-symptomatic ${ }^{9}$.

In the present study, morphological variables as size (measured as maximum diameter in millimeters), eloquence of nidus location and laterality of the nidus, anatomic AVM location classified as lobar (cortical or subcortical), deep only (the basal ganglia, internal capsule, thalamus or corpus callosum), or infratentorial were analyzed ${ }^{10}$. The number of feeding arteries and the presence of associated aneurysms were also considered. Aneurysms were classified as feeding artery aneurysms, intranidal aneurysms (both considered AVM associated), and aneurysms nonrelated to blood flow to the AVM (non-associated aneurysms). The venous drainage pattern (superficial and/or deep), the local, number and presence of stenosis or ectasias in the draining veins were also evaluated. The Spetzler-Martin classification was used to grade the AVMs ${ }^{10}$.

Univariate and multivariate statistical models were used to test the associations among demographic (sex, age), clinical (hemorrhage, seizure, focal neurological deficit, and headache), and morphological features (anatomical localization; superficial, deep, infratentorial or supratentorial location; nidus size; number of feeding arteries, compartments, and draining veins; type of venous drainage; presence of stenosis, venous ectasias, and arterial aneurysms; Spetzler-Martin classification). Data were analyzed using the Minitab Statistical Software 12.22 (Minitab Inc, State College Pennsylvania, USA) with a significance level ( $p$ ) of 0.05 .

\section{RESULTS}

Predominant age at diagnosis (64\%) was the fourth decade. The location of the nidus was lobar in 117 (69\%) patients, deep in 34 (20\%), infratentorial in 16 (9\%), and lobar/deep in 3 (2\%) (Fig 1).
Seventy-eight of the AVMs (46\%) had small nidus size $(<3 \mathrm{~cm}), 74(43 \%)$ were middle-sized $(3-6 \mathrm{~cm})$, and $18(11 \%)$ were large $(>6 \mathrm{~cm})$. There was 1 compartment in 135 cases (79\%), 2 in 23 (14\%), 3 in 3 (2\%), more than $3(1 \%)$ in 2, and not classified in $7(4 \%)$ cases. Arterial aneurysms were diagnosed in 20 (12\%) patients. Out of this group, 9 were found in AVM feeding arteries, 8 intranidal and 3 in vessels non-related to AVMs.

The AVMs were fed by branches of the middle cerebral artery in 101 (59\%) cases, by the posterior cerebral artery in 73 (43\%) cases, and by the anterior cerebral artery in $63(37 \%)$ cases. There was a single feeding artery in 20 cases (12\%), multiple in 142 (83\%) and not classified in $8(5 \%)$. Moyamoya pattern was found in $6(3.5 \%)$ cases. Superficial draining vein was observed in 76 (48\%) cases, deep in 46 (27\%), combined in $46(27 \%)$, and not classified in 4 patients (2\%). Single draining vein (Fig 2) occurred in $62(36 \%)$ patients, multiple in 105 (62\%) and not classified in $3(2 \%)$. Ectasias or venous aneurysms were found in 54 $(32 \%)$ patients and venous stenosis in $3(2 \%)$. According to the Spetzler-Martin classification, 15 (9\%) AVMs were clas-

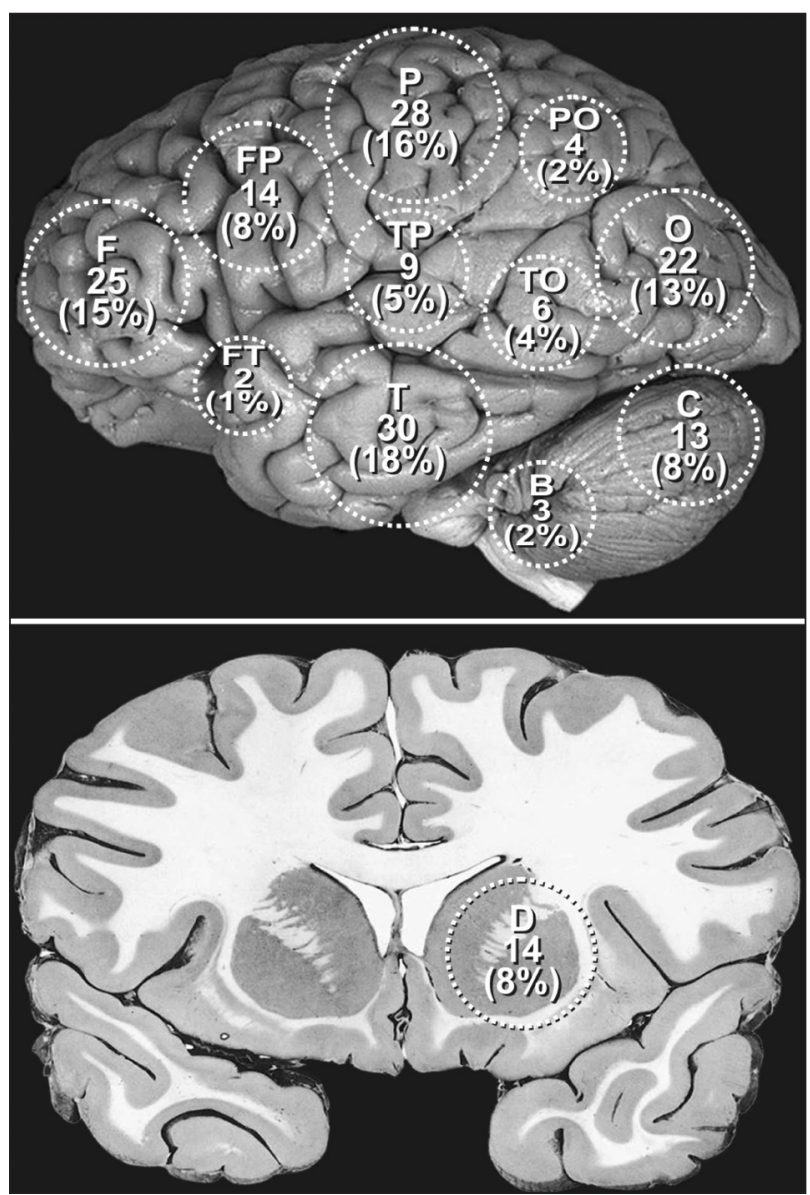

Fig 1. AVM site in 170 patients (F: frontal; FP: fronto-parietal; FT: fronto-temporal; P: parietal; T: temporal; TP: temporo-parietal; TO: temporo-occipital; C: cerebellar; O: occipital; PO: parietal-occipital; B: brain stem; $D$ : deep). 

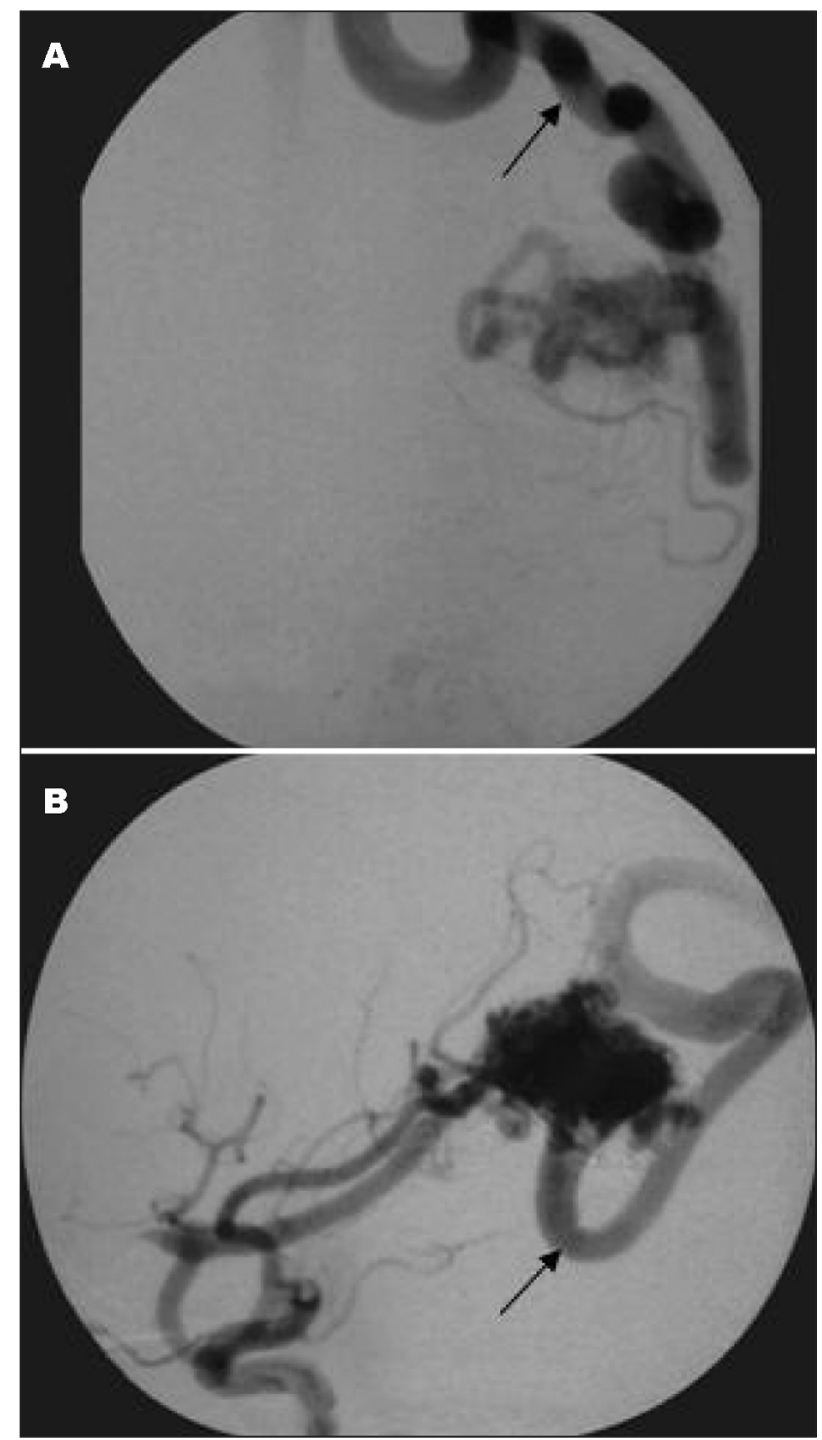

Fig 2. Angiogram of a 34-year-old female patient showing left temporo-parietal AVM with single draining vein (arrows) in anteroposterior position $[A]$ and in lateral view [B].

sified grade I, $49(28 \%)$ grade II, $55(33 \%)$ grade III, 41 (24\%) grade IV, and $10(6 \%)$ grade V.

The clinical presentations of this series AVMs at diagnosis are presented in Table. There was a statistically significant association between hemorrhage and: small nidus size $(p=0.002)$, single feeding artery $(p=0.007)$, single draining vein $(p=0.003)$. There was negative association between large nidus size $(>6 \mathrm{~cm})(p=0.002)$ and hemorrhage. No significant associations were found between hemorrhage and demographic variables, such as sex and age, as well as morphological variables, such as: deep, infratentorial or lobar location of the nidus; deep venous drainage; venous stenosis; venous ectasia; and associated aneurysms. Hemorrhage was associated with Spetzler-Martin grade I ( $p=0.049)$, but negatively with grade $V$.

The multivariate analysis showed that small nidus size
Table 1. Clinical presentations of brain arteriovenous malformations at the moment of diagnosis.

\begin{tabular}{lll}
\hline Presentation & $\mathrm{N}$ & $\%$ \\
\hline Hemorrhagic & 89 & 52 \\
Non-hemorrhagic & 70 & 48 \\
Focal neurological deficit & 68 & 42 \\
Seizure & 52 & 31 \\
Headache & 79 & 46 \\
Other & 38 & 22 \\
Non-symptomatic & 11 & 6 \\
\hline
\end{tabular}

$\mathrm{N}$ : number of occurrences.

(OR 5.57, 95\% Cl 1.55 to 20.00; $p=0.008$ ), single feeding artery and single draining vein (OR $6.08,95 \% \mathrm{Cl} 1.64$ to 22.50; $p=0.007$ ) and single compartment (OR 2.39, 95\% $\mathrm{Cl} 1.03$ to $5.56 ; \mathrm{p}=0.043$ ) were separately associated with hemorrhage. The combined presence of single feeding artery and single draining vein was significantly associated with hemorrhage $(p<0.0005)$. In the same manner, the combined presence of small nidus size (OR 3.88, 95\% $\mathrm{Cl} 1.08$ to 13.96; $\mathrm{p}=0.038$ ), single feeding artery and single draining vein (OR 4.03, 95\% Cl 1.03 to 15.80; $p=0.046$ ) was associated with hemorrhagic presentation $(p=0.005)$.

Seizures were positively correlated with large and middle nidus size $(3-6 \mathrm{~cm}$ and $>6 \mathrm{~cm}$, respectively) and negatively with small nidus size $(<3 \mathrm{~cm})(p=0.021)$. The multivariate analysis, considering age and absence of seizure as constants, showed statistically significant association $(p=0.041)$ between seizure and middle nidus size ( 3 to $6 \mathrm{~cm}$ ) (OR 2.75, 95\% Cl 1.32 to 5.75; $\mathrm{p}=0.007$ ). For AVMs with large nidus size $(>6 \mathrm{~cm})$, the correlation with seizures was near significance limit (OR 2.67, 95\% Cl 0.88 to 8.09 ; $\mathrm{p}=0.082$ ). Frontal and parietal locations as well as feeding arteries from the middle cerebral artery were positively correlated with seizure ( $p=0.002)$; while the correlation between occipital and cerebellar regions $(p=0.017)$ and deep location ( $p=0.002$ ) was negative.

\section{DISCUSSION}

In this study, AVMs were more frequent in patients aged between the third and fifth decades of life. Hemorrhage was the most frequent clinical presentation, followed by headache, focal neurological deficit, and seizure. Regarding clinical and morphological correlations, there was a significant association between hemorrhage and: grade I; small nidus size; single feeding artery; and single draining vein. AVMs with large nidus size were negatively associated with hemorrhage. There was a positive association between seizure and large nidus size, however negative for small nidus size.

Hemorrhage is the most common clinical manifestation 
of $\mathrm{AVMs}^{6,11-14}$, being responsible for fatal evolution in most cases $^{1,15}$. Our series follow these same conclusions. Some risk factors for hemorrhage include age ${ }^{9}$, sex ${ }^{12}$, pregnancy ${ }^{16}$, and hypertension ${ }^{15}$. Population-based follow-up studies demonstrate that, in the natural history, the risk of spontaneous, subarachnoid or intracerebral hemorrhage ranges from 2 to $6 \%$ per year ${ }^{3,17}$. The incidence of hemorrhage related to the location of the nidus is very controversial in the literature. For some authors, deep location predisposes to bleeding ${ }^{18}$; for others, on the contrary, hemorrhage is more frequent in cases of cortical location (temporal and occipital $)^{19}$; at last, others consider the nidus location as an inconsistent predictive factor of hemorrhage ${ }^{20}$.

In the present study, there was positive correlation between hemorrhage and small nidus size, being it negative for large nidus. However, once again the literature is controversial, although most studies establish a relationship between small nidus size and hemorrhage $e^{2,8,10,21-28}$. At first it was believed that, because larger AVMs include more frequently the cortex, the occurrence of seizure and focal neurological deficit as symptoms could be more common $^{29}$. It is possible that large or small AVM size may have the same risk of hemorrhage, but small lesions may cause less diverse symptoms (such as seizure, headache, progressive motor deficit), because they usually occur in conjunction with hemorrhage $e^{4,8,25,29}$.

Concerning feeding arteries, Mansmann et al. ${ }^{24}$, assessing 662 AVM patients, found negative association between stenosis and arterial ectasia and hemorrhage. Specific feeding arteries have also been implied as perforating arteries ${ }^{18,25}$ or originating from the vertebrobasilar system $^{18}$. In the present series, there was correlation between hemorrhage and number of the feeding arteries, however no correlation was found with regard to site of origin of these arteries.

The rate of AVM associated with arterial aneurysms in the literature varies from 4 to $58 \% \%^{2,18,30-32}$, and that seems to be related to the counting of infundibular dilatations as aneurysms ${ }^{27}$. In several series, presence and number of aneurysms in feeding arteries was significantly greater in AVM patients with hemorrhage, mainly subarachnoid ${ }^{2,18,26,31}$. However, other authors did not confirm this association ${ }^{8,23,32}$. In the present study, it is not possible to correlate the presence of arterial aneurysms with hemorrhage related to the AVM.

Several researchers emphasize the importance of the venous drainage in the pathophysiology of cerebral hemorrhage. Deep drainage frequently has been demonstrated to be a factor that increases the risk of hemorrhage $e^{9,2,28,25,27}$. This may be due to the fact that many AVMs with deep drainage are distant from the cortex, decreasing the occurrence of seizure ${ }^{25}$. Other factors were associated to AVM rupture, such as ectasia, due to the venous hypertension, venous re- cruitment, venous stenosis, number of draining veins, and

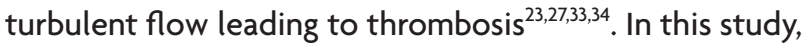
there was no association between deep and/or superficial drainage and hemorrhage. However, in accordance with the results obtained by Stefani et al. ${ }^{2}$, there was correlation between single draining vein and hemorrhage. In spite of that, the cause-effect relationship between number of draining veins and bleeding seems to be complicated by the fact that small AVMs have few drainage veins ${ }^{25}$. Nevertheless, Kader et al. ${ }^{23}$, analyzing 449 patients, considered that drainage and size may be independent risk factors of hemorrhage. In the present study, there was statistical significance for both variables, in the separate and in the combined analyses.

AVMs are initially manifested by seizure in 15 to $47 \%$ of the cases ${ }^{8,9,12,18-20,23-25,27}$, but more precisely in 20 to $30 \%$ of the cases, as the results found in this paper. Turjman et al..$^{35}$ identified 6 angioarchitectural AVM factors associated to seizure: cortical location, feeding by the middle cerebral artery, feeding by cortical artery, absence of aneurysm, presence of venous ectasia, and association of ectasic vein in the absence of arterial aneurysm. In the present study, there was association between seizure and: cortical location; and feeding artery of the middle cerebral artery. Superficial and large $(>6 \mathrm{~cm})$ AVMs, located in the temporal ${ }^{6}$, fronta $l^{19}$ or parietal ${ }^{36}$ lobes were also associated with seizure. In this series, there was correlation between seizure and frontal and parietal AVMs, but no statistical significance for temporal AVMs. Seizures may result from mass effect with cortical irritation, alterations of flow leading to deviation of blood flow, ischemia and neuronal lesion or microscopic hemorrhage and gliosis ${ }^{37,38}$. In our series, there was a negative association between seizure and small size AVMs, but a significant association between middle size AVMs and epilepsy, and bordering statistical significance in cases of AVMs larger than $6 \mathrm{~cm}$.

Headaches are common complaints in AVM patients, being it the second most frequent clinical presentation in this series with relevant association with hemorrhage, similar to the picture of ruptured cerebral aneurysms. Considering headaches as the only clinical manifestation, there was similar incidence to the encountered in the literature, which ranges from 5 to $15 \%$, $12,20,23,25-27$.

Progressive neurological dysfunction in AVM patients, including cognitive deficit, is usually related to hypoperfusion and consequent brain ischemia. It can also be related, in some cases, to small recurrent hemorrhages, mass effect, or hydrocephalia ${ }^{39}$. This series presents a rate of $9 \%$ of focal neurological deficit in unruptured AVMs, very similar to the less than $10 \%$ found in the literature $e^{4,5,26,40}$.

The results obtained in this study suggest that AVMs with small nidus, single feeding artery and single draining vein are associated to hemorrhagic presentation. With regard to morphological features, the presence of a single 
compartment appeared as a separate risk factor for hemorrhage. Hemorrhage was positively associated with Spetzler-Martin grade I and negatively with grade $V$. There was no significant correlation between aneurysm and hemorrhage. The relation between seizure and large nidus size was positive, however negative for small nidus size.

ACKNOWLEDGMENTS - We are grateful to thank Eliane dos Santos Soeiro e Patrícia Kelley de Freitas for valuable technical assistance.

\section{REFERENCES}

1. McCormick WF. The pathology of vascular ("arteriovenous") malformations. J Neurosurg 1966;24:807-816.

2. Stefani MA, Porter PJ, terBrugge KG, Montanera W, Willinsky RA, Wallace MC. Angioarchitectural factors present in brain arteriovenous malformations associated with hemorrhagic presentation. Stroke 2002;33:920-924.

3. ApSimon HT, Reef H, Phadke RV, Popovic EA. A populationbased study of brain arteriovenous malformation: long-term treatment outcomes. Stroke 2002;33:2794-2800.

4. Crawford PM, West CR, Chadwick DW, Shaw MD. Arteriovenous malformations of the brain: natural history in unoperated patients. J Neurol Neurosurg Psychiatry 1986;49:1-10.

5. Fults D, Kelly DL Jr. Natural history of arteriovenous malformations of the brain: a clinical study. Neurosurgery 1984;15: 658-662.

6. Martin NA, Vinters HV. Arteriovenous malformations. In: Carter LP, Spetzler RF, Hamilton MG (Eds). Neurovascular surgery. New York: McGraw-Hill; 1994:875-903.

7. Joint Writing Group of the Technology Assessment Committee, American Society of Interventional and Therapeutic Neuroradiology; Joint Section on Cerebrovascular Neurosurgery, a Section of the American Association of Neurological Surgeons and Congress of Neurological Surgeons; Section of Stroke and the Section of Interventional Neurology of the American Academy of Neurology. Reporting terminology for brain arteriovenous malformation clinical and radiographic features for use in clinical trials. Stroke 2001;32:1430-1442.

8. Pollock BE, Flickinger JC, Lunsford LD, Bissonette DJ, Kondziolka D. Factors that predict the bleeding risk of cerebral arteriovenous malformations. Stroke 1996;27:1-6.

9. Stapf C, Mast H, Sciacca RR, et al. Predictors of hemorrhage in patients with untreated brain arteriovenous malformation. Neurology 2006;66:1350-1355.

10. Spetzler RF, Martin NA. A proposed grading system for arteriovenous malformations. J Neurosurg 1986;65:476-483.

11. Brown RD Jr, Wiebers DO, Forbes G, et al. The natural history of unruptured intracranial arteriovenous malformations. J Neurosurg 1988;68:352-357.

12. Mast $\mathrm{H}$, Young WL, Koennecke HC, et al. Risk of spontaneous haemorrhage after diagnosis of cerebral arteriovenous malformation. Lancet 1997;350:1065-1068.
13. Lucas CP, Prandini MN, Caldas JGMP. Analysis of the best therapeutic alternative for intracranial dural arteriovenous malformations. Arq Neuropsiquiatr 2005;63:605-613.

14. Seda Jr LF, Pieruccetti MA, Freitas JMM, Listik S, Pereira CAB. Fístula arteriovenosa dural intracraniana com drenagem perimedular. Arq Neuropsiquiatr 2002;60:856-860.

15. Langer DJ, Lasner TM, Hurst RW, Flamm ES, Zager EL, King JT Jr. Hypertension, small size, and deep venous drainage are associated with risk of hemorrhagic presentation of cerebral arteriovenous malformations. Neurosurgery 1998;42:481-486.

16. Karlsson B, Lindquist C, Johansson A, Steiner L. Annual risk for the hemorrhage from untreated cerebral arteriovenous malformations. Minim Invas Neurosurg 1997;40:40-46.

17. Turjman F, Massoud TF, Viñuela F, Sayre JW, Guglielmi G, Duckwiler G. Correlation of the angioarchitectural features of cerebral arteriovenous malformations with clinical presentation of hemorrhage. Neurosurgery 1995;37:856-862.

18. Waltimo $\mathrm{O}$. The relationship of size, density and localization of intracranial arteriovenous malformations to the type of initial symptom. J Neurol Sci 1973;19:13-19.

19. Ondra SL, Troupp H, George ED, Schwab K. The natural history of symptomatic arteriovenous malformations of the brain: a 24-year follow-up assessment. J Neurosurg 1990;73:387-391.

20. Fleetwood I, Hamilton M, Flemming K, Brown Jr R, Morgan $\mathrm{M}$, Setton A. True arteriovenous malformations. In: Winn HR (Ed). Youmans Neurological Surgery. $5^{\text {th }}$ ed. Philadelphia: Saunders; 2004:2137-2291.

21. Fogarty-Mack P, Pile-Spellman J, Hacein-Bey L, et al. The effect of arteriovenous malformations on the distribution of intracerebral arterial pressures. AJNR Am J Neuroradiol 1996;17:1443-1449.

22. Henkes H, Gotwald TF, Brew S, Miloslavski E, Kämmerer F, Kühne D. Intravascular pressure measurements in feeding pedicles of brain arteriovenous malformations. Neuroradiology 2006;48:182-189.

23. Kader A, Young WL, Pile-Spellman J, et al. The influence of hemodynamic and anatomic factors on hemorrhage from cerebral arteriovenous malformations. Neurosurgery 1994;34:801-808.

24. Mansmann U, Meisel J, Brock M, Rodesch G, Alvarez H, Lasjaunias P. Factors associated with intracranial hemorrhage in cases of cerebral arteriovenous malformation. Neurosurgery 2000;46:272-281.

25. Nataf F, Meder JF, Roux FX, et al. Angioarchitecture associated with haemorrhage in cerebral arteriovenous malformations: a prognostic statistical model. Neuroradiology 1997;39:52-58.

26. Robinson JL, Hall CS, Sedzimir CB. Arteriovenous malformations, aneurysms, and pregnancy. J Neurosurg 1974;41:63-70.

27. Spetzler RF, Hargraves RW, McCormick PW, Zabramski JM, Flom RA, Zimmerman RS. Relationship of perfusion pressure and size to risk of hemorrhage from arteriovenous malformations. J Neurosurg 1992;76:918-923.

28. Raupp EF, Fernandes J. Does treatment with n-butyl cyanocrylate embolization protect against hemorrhage in cerebral arteriovenous malformations ? Arq Neuropsiquiatr 2005;63:34-39. 
29. Duong DH, Young WL, Vang MC, et al. Feeding artery pressure and venous drainage pattern are primary determinants of hemorrhage from cerebral arteriovenous malformations. Stroke 1998;29:1167-1176.

30. Halim AX, Singh V, Johnston SC, et al. Characteristics of brain arteriovenous malformations with coexisting aneurysms: a comparison of two referral centers. Stroke 2002;33:675-679.

31. Stapf C, Mohr JP, Pile-Spellman J, et al. Concurrent arterial aneurysms in brain arteriovenous malformations with haemorrhagic presentation. J Neurol Neurosurg Psychiatry 2002;73:294-298.

32. Sutherland GR, King ME, Drake CG, Peerless SJ, Vezina WC. Platelet aggregation within cerebral arteriovenous malformations. J Neurosurg 1988;68:198-204.

33. Höllerhage HG. Venous drainage system and risk of hemorrhage from AVM's. J Neurosurg 1992;77:652-653.

34. Torrico TA, Tevah CJ. Oclusión espontánea de malformación arteriovenosa cerebral parcialmente embolizada. Arq Neuropsiquiatr 2006;64:681-685.
35. Turjman F, Massoud TF, Sayre JW, Viñuela F, Guglielmi G, Duckwiler G. Epilepsy associated with cerebral arteriovenous malformations: a multivariate analysis of angioarchitectural characteristics. AJNR Am J Neuroradiol 1995;16:345-350.

36. Flemming KD, Brown Jr RD. Natural history of intracranial vascular malformations. In: Winn HR (Ed). Youmans Neurological Surgery. $5^{\text {th }}$ ed. Philadelphia: Saunders; 2004:2159-2180.

37. Mast H, Mohr JP, Osipov A, et al. 'Steal' is an unestablished mechanism for the clinical presentation of cerebral arteriovenous malformations. Stroke 1995;26:1215-1220.

38. Borges LR, Malheiros SM, Pelaez MP, et al. Associação de malformação vascular e gliomas. Arq Neuropsiquiatr 2003;61: 426-429.

39. Hartmann A, Mast H, Mohr JP, et al. Morbidity of intracranial hemorrhage in patients with cerebral arteriovenous malformation. Stroke 1998;29:931-934.

40. Lazar RM, Connaire K, Marshall RS, et al. Developmental deficits in adult patients with arteriovenous malformations. Arch Neurol 1999;56:103-106. 